Reprod. Nutr. Dévelop., 1980, 20 (6), 1893-1898.

\title{
Is the role of melatonin in induction of ovulation in the light-induced constant estrous anovulatory state mediated through the brain serotonergic system ?
}

par Carmela F. DE GAETANI*(1), Rosanna POGGIOLI**, Paola FERRARI**, B. MESS ***, G. P. TRENTINI*

Instifutes of *Pathological Anatomy and of **Pharmacology, University of Modena, Italy, and ***Department of Anatomy, University Medical School, Pécs, Hungary.

Summary. In animals in constant estrous-anovulatory (CEA) state, induced by continuous exposure to light (LL), the midbrain content of serotonin (5-HT) and 5-hydroxyindoleacetic acid (5-HIAA) decreased significantly, but no significant variations were detected in the basal hypothalamus. Late afternoon chronic melatonin treatment provoked resumption of ovulation and increased the midbrain 5-HT content. Similar results were evident after replacing LL-CEA rats in normal light-dark cycles. Melatonin appeared to mimic the effect of the daily darkness phase by eliciting ovulation; this effect might be mediated via the midbrain serotonergic system.

\section{Introduction.}

In previous papers (Mess et al., 1978 ; Trentini ef al., 1978), we demonstrated that the chronic injection of melatonin (MEL) in the late afternoon was able to overcome the constant estrous-anovulatory (CEA) state induced in the rat by exposure to continuous light (LL) for a period of 4 months. The luteinizing effect of MEL was significantly inhibited either by feeding the animals a tryptophan-poor diet or by injecting Methiothepin, a blocker of the central serotonergic and dopaminergic receptors. Moreover, it was demonstrated that both these treatments were able to significantly counteract the resumption of ovulation and of vaginal cyclicity that followed the replacement of LL-CEA rats in a normal light-dark (LD) environment (Mess ef al., 1979).

Several data in the literature (Bliss et al., 1972 ; Héry et al., 1975, 1976 ; Kordon and Ramirez, 1975 ; Wilson et al., 1974, 1977) have suggested the relevant role played by the serotonergic system in the regulation of ovulation and the possible relationship linking the pineal gland to the central serotonergic system (for survey see Mess ef al., 1978 ; Trentini et al., 1979).

(1) Correspondence to : Dr. Carmela F. de Gaetani, Institute of Pathological Anatomy, University of Modena, via Berengario 4, 41100 Modena, Italy. 
The present study provides more direct experimental evidence in favour of the hypothesis that MEL influences the brain serotonergic system which at least partly mediates the influence of the pineal gland on reproductive function.

\section{Materials and methods.}

Adult virgin female albino rats of our inbred Wistar strain were exposed to LL of uniform intensity for a period of 3 months. Vaginal smears were checked daily at $09.00 \mathrm{~h}$ after this date. Only rats which showed persistent vaginal cornification through the next 4 weeks and polyfollicular ovaries at laparotomy were considered to be CEA animals and were used for further experiments; those showing any corpora lutea were discarded.

The LL-CEA rats were then divided into 3 experimental groups :

Group 1 , treated daily with $0.1 \mathrm{ml}$ of 1 p. 100 alcoholic saline ;

Group 2, treated daily with $100 \mu \mathrm{g}$ of MEL in $0.1 \mathrm{ml}$ of $1 \mathrm{p} .100$ alcoholic saline ;

Group 3, replaced in a light-dark environment $(14: 10 \mathrm{hrs}$ light-dark ; lights on $06.00-$ $20.00 \mathrm{~h}, \mathrm{LD})$ and treated daily with $0.1 \mathrm{ml}$ of $1 \mathrm{p} .100$ alcoholic saline.

All injections were done subcutaneously at about $20.00 \mathrm{~h}$ and continued for a period of time varying from 5 to 15 days. Another group of animals (group 4) of the same age, used as a control, was maintained during the time of the experiment under the same light-dark conditions and treated as previously reported with alcoholic saline. Only rats showing regular 4-day vaginal cycles were used as controls. The animals of groups 2 and 3 were killed by decapitation on the estrous day of the first estrous cycle following the diestrous phase induced either by MEL treatment or by replacement in LD conditions. Immediately after sacrifice the midbrain, medial basal hypothalamus and a piece of the cerebral cortex were rapidly dissected and deeply frozen. Ovulation was tested by searching for tubal ova. Only specimens of animals positive for tubal ova were retained for biochemical determinations. Rats of groups 1 and 4 were killed in parallel with animals of groups 2 and 3 . All the animals were killed between 11.00 and $12.00 \mathrm{~h}$ on the day of estrus.

The levels of 5-HT and of 5-hydroxyindoleacetic acid (5-HIAA) in the different areas of the brain were assayed spectrofluorimetrically using a modification of the method of Curzon and Green (1970). Individual specimens were homogenized in $7 \mathrm{ml}$ of acid butanol and centrifuged at $6500 \times \mathrm{g}$ at $2{ }^{\circ} \mathrm{C}$ for $10 \mathrm{~min}$. The supernatant was pipetted into a 25- $\mathrm{ml}$ glass stoppered tube and shaken mechanically for $5 \mathrm{~min}$ with $1 \mathrm{ml}$ of L-cysteine $(0.1 \mathrm{~N} \mathrm{HCl} 0.1 \mathrm{p}$. 100 solut.) and $25 \mathrm{ml}$ of $\mathrm{n}$-heptane. Two phases, $A$ and $B$, were separated by $1000 \times \mathrm{g}$ centrifugation for $3 \mathrm{~min}$. In order to assay 5-HIAA, $10 \mathrm{ml}$ of organic phase $A$ were collected in a glass tube with $1 \mathrm{ml}$ of $0.5 \mathrm{M}$ phosphate buffer, $\mathrm{pH} \mathrm{7,} \mathrm{shaken} \mathrm{mechanically} \mathrm{for} 5 \mathrm{~min}$, and centrifuged at $1000 \times \mathrm{g}$ for $3 \mathrm{~min} .0 .5 \mathrm{ml}$ of the phosphate aqueous phase were added to $1 \mathrm{ml}$ of concentrated $\mathrm{HCl}, 0.1 \mathrm{ml} \mathrm{N} \mathrm{HCl}$ containing 0.1 p. 100 L-cysteine, and $0.2 \mathrm{ml}$ of a 0.1 p. 100 O-phthalaldehyde (OPT) methanol solution. In order to determine 5-HT, $0.5 \mathrm{ml}$ of the aqueous phase $B$ were pipetted into a test tube with $0.1 \mathrm{ml}$ of a $0.1 \mathrm{p} .100$ OPT methanol solution and $1 \mathrm{ml}$ of concentrated $\mathrm{HCl}$. After stirring and heating in boiling water for $10 \mathrm{~min}$, the tubes were cooled, and 5-HT and 5-HIAA fluorescence 
was measured in an Aminco Bowman spectrophotofluorometer at wavelengths of $360 / 480 \mathrm{~nm}$.

5-HT and 5-HIAA standard stock solutions were prepared as $100 \mu \mathrm{g} / \mathrm{ml}$ in $0.1 \mathrm{~N} \mathrm{HCl} ; 0.5 \mu \mathrm{g}$ was added to homogenized tissue blank and reagent blank. The tissue blank standards were processed as the. samples, including separation between butanol and aqueous phases. Reagent blank standards were added immediately before L-cysteine and OPT. The recovery of 5-HT and 5-HIAA was found to be 90 and 75 p. 100 respectively.

The significance of the differences between groups was determined using oneway ANOVA and the F-test. A value for $P$ of $<0.05$ was regarded as significant.

\section{Results.}

The exposure to $L L$ provoked the CEA syndrome with polyfollicular ovaries in 92 p. 100 of the rats (fable 1). It also significantly decreased the 5-HT content of

TABLE 1

Occurrence of ovulation in continuous light-constant estrous anovulatory (LL-CEA) rats affer melatonin treatment (MEL) or replacement in normal light-dark (LD) cycles

\begin{tabular}{|c|c|c|c|}
\hline \multirow[b]{2}{*}{ Treatment } & \multicolumn{2}{|c|}{ Occurrence of ovulation } & \multirow{2}{*}{$\begin{array}{l}\text { Statistical } \\
\text { significance }\end{array}$} \\
\hline & $\frac{\text { No. ovulating }}{\text { No. treated }}$ & Percent & \\
\hline $\begin{array}{l}\text { 1. LL } \ldots \ldots \ldots \ldots \\
\text { 2. LL-MEL } \ldots \cdots \cdots \\
\text { 3. LL-LD } \ldots \ldots \ldots \ldots\end{array}$ & $\begin{array}{r}2 / 25 \\
17 / 25 \\
15 / 20\end{array}$ & $\begin{array}{r}8 \\
68 \\
75\end{array}$ & $\begin{array}{l}P<0,01 \text { vs } 1 \\
P<0,01 \text { vs } 1\end{array}$ \\
\hline
\end{tabular}

the midbrain $(P<0.01)$, as compared with the levels of the control rats exposed to normal LD cycles, and significantly reduced the mesencephalic content of 5-HIAA (table 2). However, the hypothalamic levels of neither compound presented significant variations. In experimental groups 2 and 3, either MEL treatment or replacement in an LD environment provoked the resumption of ovulation in a large majority of the LL-CEA rats (table 1). Both treatments also induced significant changes in the 5-HT and 5-HIAA values. In particular, MEL treatment overcame the CEA syndrome and induced a significant rise in the 5-HT content of the midbrain that reached values similar to those of the LD controls. The 5-HIAA levels also presented an apparent increase which, however, did not reach the limit of statistical significance. On the other hand, the increase in the midbrain content of 5-HIAA, highly significant in animals replaced in LD cycles, was accompanied by a parallel increase of the 5-HT level. No significant variations were detected in the basal hypothalamus after either treatment, with the exception of a decrease of 5-HT content in MEL-treated animals, which was only significant when compared with that of the LD controls. Finally, no appreciable changes were detected in the 5-HT or the 5-HIAA content of the cerebral cortex under the different experimental conditions. 
TABLE 2

Changes in hypothalamic and mesencephalic levels of serotonin (5-HT) and of 5-hydroxyindoleacetic acid (5-HIAA) in LL-CEA rats ovulating after chronic melatonin (MEL) treatment or replacement in normal light-dark (LD) cycles

\begin{tabular}{|c|c|c|c|c|c|}
\hline \multirow[b]{2}{*}{ Treatment } & \multirow[b]{2}{*}{ No. } & \multicolumn{2}{|c|}{ Basal hypothalamus } & \multicolumn{2}{|c|}{ Mesencephaton } \\
\hline & & $\begin{array}{c}5-H T \\
(\mu g / g)\left({ }^{1}\right)\end{array}$ & $\begin{array}{c}\text { 5-HIAA } \\
(\mu \mathrm{g} / \mathrm{g})\end{array}$ & $\begin{array}{c}5-\mathrm{HT} \\
(\mu \mathrm{g} / \mathrm{g})\end{array}$ & $\begin{array}{c}5 \text {-HIAA } \\
(\mu \mathrm{g} / \mathrm{g})\end{array}$ \\
\hline $\begin{array}{l}\text { 1. LL } \ldots \ldots . . \\
\text { 2. LL-MEL ... } \\
\text { 3. LL-LD } \ldots \\
\text { 4. LD } \ldots .\end{array}$ & $\begin{array}{l}23 \\
10 \\
11 \\
10\end{array}$ & $\begin{array}{l}5.052 \pm 0.901 \\
2.668 \pm 0.451 \\
4.475 \pm 0.947 \\
5.509 \pm 0.521\left(^{a}\right)\end{array}$ & $\begin{array}{l}1.456 \pm 0.317 \\
1.243 \pm 0.421 \\
2.292 \pm 0.845 \\
1.976 \pm 0.461\end{array}$ & $\begin{array}{l}1.850 \pm 0.144 \\
2544 \pm 0.202\left({ }^{b}\right) \\
3.187 \pm 0.691\left(^{b}\right) \\
2.877 \pm 0.291(c)\end{array}$ & $\begin{array}{l}0.969 \pm 0.148 \\
1.276 \pm 0.129 \\
1.902 \pm 0.326(c) \\
1.624 \pm 0.175(b)\end{array}$ \\
\hline
\end{tabular}

(1) Mean \pm SEM ; (a) $\mathrm{P}<0.01$ vs group $2 ;\left(^{(b)} \mathrm{P}<0.05\right.$ vs group $1 ;\left(^{c}\right) \mathrm{P}<0.01$ vs group 1.

\section{Discussion.}

The present study demonstrates that exposure to $L L$ induces a marked decrease in the 5-HT content of the midbrain and blocks ovulation and vaginal cyclicity at $12.00 \mathrm{~h}$ under our experimental conditions. LL does not appear to significantly modify the 5-HT metabolism of the basal hypothalamus. The results show, moreover, that the re-establishment of ovulation, induced by daily MEL treatment in the late afternoon (onset of darkness for control rats), was accompanied by a significant increase in the midbrain content of 5-HT and a lesser increase in 5-HIAA, which nearly reached the values presented by the control rats exposed to normal LD cycles. Similar changes in the midbrain serotonergic system accompanied the resumption of ovulation in $L L$ rats replaced in normal LD cycles. On the contrary, neither MEL treatment nor replacement in LD cycles appeared to modify the 5-HT content of the medial basal hypothalamus, as compared with that of LL animals. However, MEL resulted in a significant decrease in the hypothalamic content of 5-HT, as compared with that of LD rats, but without significantly changing the 5-HIAA level. Further experiments are in progress to verify the true value of these data.

These results, demonstrating that the process of overcoming the CEA syndrome keeps pace with the apparent normalization of the midbrain 5-HT content; lend support to the previous hypothesis (Trentini ef al., 1978 ; Mess ef al., 1979) that MEL acts via the central serotonergic system in eliciting ovulation. On the other hand, it seems unlikely that these two effects take place independently, because similar effects were also observed in LL rats replaced in normal light-dark cycles. Thus, MEL administration in the late afternoon appears to mimic the action of light extinction on the midbrain serotonergic system in LL-CEA rats. Accordingly, the physiological role of the pineal gland is that of a biological clock informing the organism of the nyctohemeral rhythm, mainly through the secretion of MEL stimulated by darkness (Wurtman and Axeirod, 1965).

The present results also support the assumption (Trentini et al., 1974, 1978) that a possible critical balance between the brain-stem 5-HT levels and the LHRH mobilizing mechanisms might be required to elicit ovulation. 
Recent data favour the idea that 5-HT does not exert a simple inhibitory role in cyclic LH release, and a separafe positive action has been repeatedly reported (Héry et al., 1975, 1976 ; Kordon and Ramirez, 1975 ; Marko and Flückiger, 1976 ; Wilson et al., 1974, 1977). Using intracerebral injections of 5,7-dihydroxytryptamine into the dorsal or median raphe of the rat, Meyer (1978) demonstrated a marked inhibition of ovulation and a significant decrease in 5-HT uptake in the suprachiasmatic nuclear region, indicative of the destruction of serotonergic inputs to that region. He concluded that this input to the suprachiasmatic nuclear region from at least the dorsal, and possibly the median, raphe nuclei seems to play a facilitating role in the control of rat ovulatory mechanisms.

The changes in the midbrain 5-HT concentration, demonstrated in the present experiments following MEL treatment, or return to normal LD cycles are associated with the resumption of ovulation provoked by MEL. Therefore, the anti-antigonadotropic effect exerted by MEL in the CEA syndrome, induced by exposure to $L L$, could be exerted via the midbrain serotonergic system.

In the light of these results, it might be correct to infer that either the antigonadotropic or the anti-antigonadotropic activity (for survey see : Mess ef al., 1978) exhibited by MEL in the regulation of ovulation, could represent only indirect effects, related to the functional state of the brain-stem serotonergic system. Accordingly, it could be hypothesized that the role played by MEL in the regulation of ovulation would express the general action that MEL exerts on the central nervous system through variations in the brain 5-HT levels (Antón-Tay et al., 1971 ; Koella, 1969 ; Krapp, 1977 ; Sjoerdsma ef al., 1970).

Reçu en avril 1980. Accepté en juillet 1980.

Acknowledgments. - This work was supported by grants from the National Research Council of Italy (78.02316.04) and the Administration Council of the University of Modena, Italy.

Résumé. Chez des rats en œstrus anovulatoire permanent (OAP) induit par une exposition en lumière continue (LL), une diminution significative du taux de 5-hydroxytryptamine (5-HT) et d'acide-5-hydroxyindole acétique (5-HIAA) mésencéphalique apparaît. Cependant, aucune variation significative de ces indoles n'est décelable dans l'hypothalamus basal. Un traitement chronique par la mélatonine, injectée tout à fait en fin d'aprèsmidi, induit la reprise de l'ovulation et accroît le taux de 5-HT mésencéphalique. Des résultats semblables sont obtenus en replaçant les animaux OAP-LL dans un environnement à cycle jour-nuit normal. II apparaît que la mélatonine mime l'effet de la phase obscure journalière en induisant l'ovulation et que cef effet pourrait s'exercer par l'intermédiaire du sysième sérotonergique mésencéphalique.

\section{References}

ANTON-TAY F., DIAZ J. L., FERNANDEZ-GUARDIOLA A., 1971. On the effect of melatonin upon human brain. Its possible therapeutic implications. Life Sci., 10, 841-850.

BLISS E. L., FRISCHAT A., SAMUELS L., 1972. Brain and festicular function. Life Sci., 11, 231-238.

CURZON G., GREEN A. R., 1970. Rapid method for the determination of 5-hydroxytryptamine and 5-hydroxyindoleacetic acid in small regions of rat brain. Brit. J. Pharmacol., 39, 653-655. 
HÉRY M., LAPLANTE E., PATTOU E., KORDON C., 1975. Interaction de la sérotonine cérébrale avec la libération cyclique de LH chez la ratte. Ann. Endocrinol. Paris, 38, 123-130.

HÉRY M., LAPLANTE E., KORDON C., 1976. Participation of serotonin in the phasic release of LH. I. Evidence from pharmacological experiments. Endocrinology, 99, 496-503.

KOELLA W. P., 1969. Serotonin and sleep. Exp. Med. Surg., 27, 157-168.

KORDON C., RAMIREZ V. D., 1975. New developments in the neural regulation of LH-RH, 271-286. In RASPÉ G., Advances in the biosciences, Pergamon Press, Oxford.

KRAPP Ch., 1977. Der Einfluss der Epiphyse auf die Lokomotionsaktivifät bei Ratten. Experientia Bosel, 33, 731-732.

MARKO M., FLÜCKIGER E., 1976. Inhibition of ovulation in rats by antagonists to serotonin and by a new tricyclic compound. Experientia Basel, 32, 491-492.

MESS B., TRENTINI G. P., TIMA L., 1978. Role of the pineal gland in the regulation of ovulation. Akademiai Kiadó, Budapest.

MESS B., TRENTINI G. P., DE GAETANI C. F., 1978. Effect of melatonin on induction of ovulation in the light-induced constant estrous-anovulatory rat. J. neural Transm., suppl. 13, 379-380.

MESS B., TRENTINI G. P., RUZSAS Cs., DE GAETANI C. F., 1979. Possible role of the brain serotoninergic neuron system in inducing ovulation in the light-induced constant estrous anovulatory syndrome, 37-43. In TALWAR G. P., Recent advances in reproduction and regulation of fertility, Elsevier, Amsterdam.

MEYER D. C., 1978. Hypothalamic and raphe serotoninergic system in ovulation control. Endocrinology, 103, 1067-1074.

SJOERDSMA A., LOVENBERG W., ENGLEMAN K., CARPENTER W. T. Jr., WYATT R. J., GESSA G. L., 1970. Serotonin now : clinical implications of inhibiting its synthesis with parachlorophenylalanine. Ann. int. Med., 73, 607-629.

TRENTINI G. P., TIMA L., DE GAETANI C. F., MESS B., 1974. Luteinization induced by p-chlorophenylalanine treatment in constant œestrous anovulatory rats. Steroids Lipids Res., 5, 262 267.

TRENTINI G. P., MESS B., DE GAETANI C. F., RUZSAS Cs., 1978. Effect of melatonin on induction of ovulation in the light-induced constant estrous-anovulatory syndrome and possible role of the brain seroloninergic system. J. endocr. Invest., 1, 305-310.

TRENTINI G. P., MESS B., DE GAETANI C. F., RUZSAS Cs., 1979. Pineal-brain relationship. Progr. Brain Res., 52, 341-365.

WILSON C. A., ENDERSBY C. A., MCDONALD P. G., 1974. Potentiating effect of serotonin on pregnant mare serum gonadotrophin-induced ovulation in the underweight immature rat. J. Endocrinol., 61, XXV.

WILSON C. A., ANDREWS M., HADLEY J. C., LEMON M., YEO T., 1977. The role of hypothalamic serotonin (5HT) before ovulation in immature rats treated with pregnant mare serum (PMS). Psychoneuroendocrinology, 2, 267-274.

WURTMAN R. J., AXELROD J., 1965 . The pineal gland. Sci. Am., 213, 50-60. 